\title{
UM ESTUDO DIAGNÓSTICO DO CONSUMO DE ÁGUA PELA IRRIGAÇÃO NA BACIA DO RIO MIRINGUAVA, REGIÃO METROPOLITANA DE CURITIBA, PARANÁ
}

\author{
A Diagnostic Study of the Water Consumption for the Irrigation \\ in the Basin of Rio Miringuava, Metropolitan Region of \\ Curitiba, Parana
}

\author{
Denise Maria Gineste ${ }^{1}$ \\ Edilberto Nunes de Moura ${ }^{2}$
}

\section{Resumo}

A principal finalidade da irrigação é fornecer água às plantas de forma sustentável sem comprometer o meio ambiente. Em nível mundial, a agricultura irrigada é a atividade que mais utiliza água doce, demandando mais de $70 \%$ dos recursos hídricos disponíveis, porém, nem sempre toda a água é utilizada de forma adequada. Métodos de irrigação mal projetados, má distribuição das chuvas e o fornecimento de água às plantas em quantidades maiores do que realmente necessitam são alguns dos principais problemas do uso inadequado desse recurso natural tão precioso. Os objetivos deste trabalho são estimar o consumo de água utilizada pelos agricultores residentes ao longo da Bacia do Rio Miringuava, Município de São José dos Pinhais, Região Metropolitana de Curitiba, identificar os sistemas de irrigação utilizados, relacionar o uso adequado destes sistemas com o consumo de água correspondente e verificar se existe um manejo adequado da água utilizada pelos sistemas irrigantes ali encontrados. Um estudo de caso foi utilizado, em que foram escolhidas aleatoriamente 33 propriedades rurais em comunidades localizadas ao longo da Bacia e submetidas a um questionário para identificar os procedimentos referentes à irrigação no local. Após constatações em campo, verificou-se que as propriedades rurais possuem áreas entre 3 a 7 hectares e que mais da metade delas apresentam áreas irrigadas iguais ou superiores a 50\%. A água é captada principalmente de reservatórios, por meio de bombas hidráulicas acionadas por motores movidos por energia gerada por óleo diesel. O método de irrigação mais utilizado é a aspersão convencional, encontrado em $91 \%$ das propriedades. A Bacia do Miringuava é uma localidade significativa na produção de hortaliças no país. A técnica da irrigação se justifica na região devido às constatações de má distribuição da precipitação ao longo do ano. 0 uso da água pelos agricultores se faz de maneira rudimentar, sem programas específicos baseados em critérios técnicos, causando um consumo acima do necessário.

Palavras-chave: Água; Agricultura; Irrigação.

Engenheira Ambiental - PUCPR

2 Doutor em Irrigação e Drenagem, Professor Adjunto PUCPR, BR116 - km 14, Costeira C.P. 129, CEP $83010-500$ - São José dos Pinhais - PR. 


\section{Abstract}

The main purpose of the irrigation is to supply water to the plants in sustainable form without compromising the environment. In world-wide level, irrigated agriculture is the activity that more demand fresh water, reaching more than $70 \%$ of the available water resources, however, the water eventually is not adequately used. Irrigation projects badly conceived, bad distribution of rains and the excess water supply to the plants are some of the main problems of the inadequate use of this so precious natural resources. The objectives of this work are to esteem the water consumption used for the agriculturists that are living on the Rio Miringuava Basin, municipality of Sao Jose dos Pinhais, Metropolitan Region of Curitiba, to identify the used systems of irrigation, to relate the adequate use of these systems with the corresponding water consumption and to verify if exists an adequate handling of the water used for the irrigations systems commonly used. A case study it was used, where 33 properties in communities located on Basin and randomly submitted to answer a questionnaire referring to local imigation procedures. After field analysis, it was verified that the size of the properties situated between 3 the 7 hectares and that more than the half of them presents $50 \%$ or more irrigated areas. The water is caught mainly of reservoirs, by means of hydraulical bombs that work with engines moved by oil diesel energy. The irrigation method commonly used is the conventional aspersion ( $91 \%$ of the properties). The Miringuava Basin is a significant locality in the vegetables production in the country. The irrigation technique is justified in the region due to the irregular precipitation distribution throughout the year. The use of the water by the agriculturists is rudimentarily made, without specific programs based in technical criteria, causing an excessive consumption.

Keywords: Water; Agriculture; Irrigation.

\section{Introdução}

Em nível mundial, a agricultura irrigada é a atividade que mais utiliza água, demandando mais de 70\% dos recursos hídricos disponíveis e, em muitos casos, com um aproveitamento médio inferior a $40 \%$. Os outros $60 \%$ são desperdiçados porque se aplica água em excesso, irriga-se fora do período de necessidade da planta em horários de maior evaporação do dia, utilizam-se técnicas de irrigação inadequadas ou ainda pela falta de manutenção nesses sistemas de irrigação (KARAM, 2001).

O principal objetivo da irrigação consiste em fornecer água às culturas de forma eficiente, evitando ao máximo criar grandes impactos ao meio ambiente. Cada vez mais aumenta a dependência à tecnologia e as condições de aproveitamento serão mais difíceis, além de maiores custos de energia para captação, adução e distribuição (MOURA, 1999).

No que se refere à produção de alimentos, a irrigação constitui-se em uma das tecnologias mais eficientes da agricultura. Embora seja uma técnica recomendada, nos últimos anos ela vem sendo considerada a vilã do desperdício de água e contaminação de recursos hídricos. Isso pode ser verdade, em sistemas irrigados onde a água e a cultura estiverem sendo manejadas de forma incorreta ou por falta de tecnologia disponível na área produtora.
Convém ressaltar que o volume de água doce disponível na Terra é o mesmo há milhões de anos. Esse volume encontrado, tanto de água doce, como de água salgada, sempre foi suficiente para suprir as necessidades de todas as formas de vida (TUNDISI, 2003).

Considerando a importância do uso da água na agricultura, este trabalho visou identificar como se procede o consumo de água na agricultura e para verificar a existência do manejo racional desse recurso na Bacia do Rio Miringuava, localizada no município de São José dos Pinhais, Região Metropolitana de Curitiba.

O modelo de agricultura que se pratica na Região Metropolitana de Curitiba sofre influência de vários fatores importantes como tipo de solos, processo de ocupação, proximidade de Curitiba e disponibilidade de água. A produção se distribui em torno do núcleo urbano. Na proximidade inicial, coexistindo com as Bacias Hidrográficas de importância como manancial urbano, concentrase 0 cultivo de hortaliças.

Esta avaliação de demanda hídrica utilizada na agricultura depende de quatro aspectos principais:

- Evapotranspiração;

- Tipo de cultura e estágio de desenvolvimento;

- Precipitação;

- Método de irrigação e sua eficiência. 
Há uma demanda estimada em mais de $790 \mathrm{~m}^{3} / \mathrm{s}$ de água para atender a irrigação em nosso País (REBOUÇAS, 1999).

Para a realização deste trabalho, dados do SIMEPAR - Sistema Meteorológico do Paraná - foram analisados para ilustrar a relação

\section{FIGURA 1 - Evapotranspiração}

Figure 1 - Evapotranspiration entre demanda (evapotranspiração) e fornecimento (precipitação). A série histórica temporal está compreendida entre 1986 e 1997, utilizando-se médias mensais e o resultado está resumido na Figura 1.



Dados: SIMEPAR (1986 - 1997).

Embora as médias anuais de precipitação no Estado do Paraná sejam relativamente altas, a imigação é necessária em algumas regiões em função da má distribuição das chuvas, da capacidade limitada de armazenamento de alguns solos, e da extrema sensibilidade de algumas culturas à falta de água. Esses fatores e as implicações econômicas da falta ou do excesso de água requerem que as irrigações sejam planejadas tão eficientemente quanto possíveis.

No período de menor índice de precipitação é necessánia a rega, geralmente meses de Janeiro a Março, mas o que não se apresenta evidente é a quantidade de água e a freqüência que essa é utilizada.

\section{Material e Métodos} nário foram:

As informações levantadas neste questio-

Rev. Acad., Curitiba, v.4, n.1, p. 21-30, jan./mar. 2006.
- Dados gerais: proprietário, área total, área irrigada, tempo na atividade e cultivo;

- Sistema de irrigação utilizado;

- Assistência técnica;

- Freqüência da visita;

- Programa de Rega: tempo de duração, freqüência da irrigação, condições de manutenção e vazão estimada;

- Captação: rio, reservatório ou poço;

- Energia consumida: elétrica ou a diesel;

- Gasto energético;

- Utilização de quimigação;

- Conhecimento da Lei de Outorga de Direito de Uso da Água.

Os trabalhos de avaliação foram divididos em coleta de dados de campo, processamento e obtenção dos resultados e as conclusões que posteriormente foram apresentadas graficamente. 
TABEIA 1 - Características gerais das propriedades.

Table 1 - General characteristics of the properties.

\begin{tabular}{|c|c|c|c|c|}
\hline Área/ produtor & $\begin{array}{l}\text { Área } \\
\text { irrigada/produtor }\end{array}$ & $\begin{array}{l}\text { \% de área } \\
\text { irrigada da } \\
\text { área total }\end{array}$ & $\begin{array}{l}\text { Tempo na } \\
\text { atividade }\end{array}$ & Cultivo \\
\hline 3,00 ha & 2,00 ha & $66,66 \%$ & 20 anos & Hortaliças \\
\hline 3,63 ha & 3,63 ha & $100,00 \%$ & 28 anos & Hortaliças \\
\hline 3,63 ha & 2,42 ha & $66,66 \%$ & 18 anos & Hortaliças \\
\hline 3,63 ha & 2,42 ha & $66,66 \%$ & 28 anos & Hortaliças \\
\hline 4,84 ha & 4,84 ha & $100,00 \%$ & 30 anos & Morango \\
\hline 4,84 ha & 2,42 ha & $50,00 \%$ & 37 anos & Hortaliças \\
\hline 4,84 ha & 2,42 ha & $50,00 \%$ & 35 anos & Morango \\
\hline 4,84 ha & 2,42 ha & $50,00 \%$ & 33 anos & Hortaliças \\
\hline 4,84 ha & 4,84 ha & $100,00 \%$ & 5 anos & Hortaliças \\
\hline 4,84 ha & 2,42 ha & $50,00 \%$ & 39 anos & Hortaliças \\
\hline 5,00 ha & 1,00 ha & $20,00 \%$ & 20 anos & Hortaliças \\
\hline 6,05 ha & 6,05 ha & $100,00 \%$ & 25 anos & Morango \\
\hline 7,26 ha & 3,63 ha & $50,00 \%$ & 24 anos & Hortaliças \\
\hline 7,26 ha & 7,26 ha & $100,00 \%$ & 25 anos & Hortaliças \\
\hline 7,26 ha & 6,05 ha & $83,33 \%$ & 42 anos & Hortaliças \\
\hline 7,26 ha & 2,42 ha & $33,33 \%$ & 31 anos & Hortaliças \\
\hline 7,26 ha & 4,84 ha & $66,66 \%$ & 30 anos & Hortaliças \\
\hline 7,26 ha & 3,63 ha & $50,00 \%$ & 34 anos & Hortaliças \\
\hline 7,26 ha & 7,26 ha & $100,00 \%$ & 30 anos & Hortaliças \\
\hline 7,26 ha & 4,84 ha & $66,66 \%$ & 46 anos & Hortaliças \\
\hline 8,47 ha & 4,84 ha & $57,14 \%$ & 45 anos & Hortaliças \\
\hline 9,68 ha & 3,63 ha & $37,50 \%$ & 48 anos & Hortaliças \\
\hline 9,68 ha & 7,26 ha & $75,00 \%$ & 43 anos & Hortaliças \\
\hline 9,68 ha & 9,68 ha & $100,00 \%$ & 40 anos & Hortaliças \\
\hline 12,10 ha & 2,42 ha & $20,00 \%$ & 35 anos & Hortaliças \\
\hline 12,10 ha & 7,26 ha & $60,00 \%$ & 30 anos & Hortaliças \\
\hline 14,50 ha & 4,00 ha & $27,58 \%$ & 18 anos & Hortaliças/Morango \\
\hline 14,52 ha & 6,05 ha & $41,66 \%$ & 40 anos & Hortaliças \\
\hline 14,52 ha & 4,84 ha & $33,33 \%$ & 27 anos & Hortaliças \\
\hline 16,94 ha & 4,84 ha & $28,57 \%$ & 30 anos & Hortaliças \\
\hline 19,36 ha & 2,42 ha & $12,50 \%$ & 45 anos & Hortaliças \\
\hline 19,36 ha & 12,10 ha & $62,50 \%$ & 47 anos & Hortaliças \\
\hline 24,20 ha & 9,68 ha & $40,00 \%$ & 26 anos & Hortaliças \\
\hline
\end{tabular}

Total 33 agricultores 


\section{Resultados e discussão}

Aleatoriamente, 33 propriedades foram submetidas ao questionário. A Tabela 1 apresenta a área total da propriedade por agricultor entrevistado, a área irrigada e a porcentagem que essa representa quando comparada à área total, o tempo na atividade e o tipo de cultivo produzido.

Verificou-se que a maioria dos agricultores, mais precisamente 20 dos 33 entrevistados, possuem área entre 3 a 7 hectares e que desses, 23 apresentam áreas irrigadas iguais ou superiores a $50 \%$, constando que utilizam grandes quantidades de água em suas propriedades.

Dos produtores, 94\% mostraram desconhecer informações fundamentais, como a vazão estimada dos sistemas de irrigação. Sem essa informação foi impossível estimar o tempo diário de aplicação de água para atender o consumo das plantas.

Sobre a freqüência e tempo de irrigação, os resultados obtidos foram bastante distintos. Alguns deles irrigam todos os dias por mais ou menos uma hora nos períodos secos e, quando necessário, no período chuvoso. Outros irrigam meia hora durante três dias semanais no período seco. Alguns disseram que a irrigação depende da cultura, mas que, por precaução, irrigam no mínimo 2 vezes por semana, durante 30 a 40 minutos. Ainda nesse quesito, há os que irrigam o tempo que eles acham necessário para nutrir a planta, independente do horário da rega, ou o tempo que o sistema permanece em funcionamento.

Por esta avaliação, percebeu-se que os agricultores não possuem nenhuma preocupação com a quantidade de água que utilizam. Eles sabem que a irrigação é necessária e que se a água está disponível, a rega é feita independente dos critérios recomendados.
Ainda sobre a eficiência, a condição de manutenção dos equipamentos usados no método de irrigação é um ponto importante. Se um sistema apresentar boas condições no uso da água, ele se tornará eficiente e correto. Mas o encontrado no local de estudo é preocupante. Dos 30 agricultores que utilizam o método por aspersão, todos disseram haver vazamentos constantes e que esse acontecimento é normal. Os reparos são feitos quando o sistema passa a não mais operar de forma correta, ou seja, em último caso.

O manejo de água é a questão mais importante nos diversos sistemas de irrigação, constituindo-se em uma das principais causas do desperdício de água, da contaminação dos recursos hídricos e do insucesso de muitos projetos. Conforme Lunardon (2003) no projeto IRRIGAÇÃO NA MADRUGADA, assumindo-se que por meio de um grande programa de conscientização sobre o uso racional da água na irrigação e de geração, ajuste e transferência de tecnologias, se consiga reduzir em média $1 \mathrm{~mm} /$ dia a água aplicada nas áreas irrigadas, isso equivalenia a $10 \mathrm{~m}^{3} / \mathrm{ha} / \mathrm{dia}$. Em 3.000 .000 ha, hoje sob irrigação, no Brasil, corresponderia numa economia de $30.000 .000 \mathrm{~m}^{3} / \mathrm{dia}$. Assumindo que se irriga em média apenas durante 180 dias/ ano, a economia total seria de $5.400 .000 .000 \mathrm{~m}^{3} /$ ano. Contudo, não se pode esquecer que a racionalização da irrigação, mediante um manejo tecnicamente orientado, trará um outro benefício tão ou mais importante do que a economia de água: 0 de reduzir a contaminação desses recursos hídricos por químicos lixiviados devido ao excesso de água em uma irrigação mal manejada.

Na Tabela 2 organizou-se os dados de maneira a verificar a origem da água utilizada para irrigação, qual o gasto energético do método utilizado e se os entrevistados obtinham alguma informação sobre a lei de Outorga de Direito de Uso da Água. 
TABELA 2 - Captação de água, energia consumida e Lei da Outorga.

Table 2 - Water caught, consumed energy and Law of Granting.

\begin{tabular}{lc|lc|cc}
\hline Captação de água & Energia consumida & \multicolumn{2}{|c}{$\begin{array}{l}\text { Conhecimento da lei de outorga } \\
\text { de direito de uso da água }\end{array}$} \\
\hline Rio & 2 & Elétrica & 6 & Sim & 29 \\
Poço & 0 & Diesel & 27 & Não & 4 \\
Reservatório & 31 & & & \\
\hline
\end{tabular}

As Figuras seguintes, 2, 3 e 4 identificam as porcentagens representativas da tabela anterior.

FIGURA 2 - Captação da água para irrigação.

Figure 2 - Water caught for irrigation.

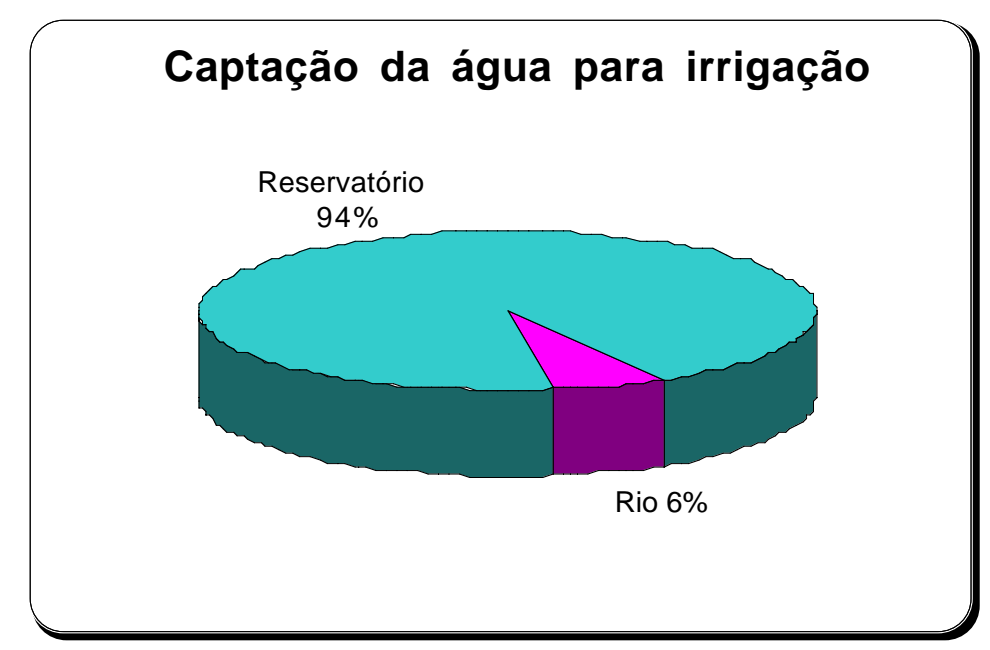

Quanto à captação de água, 94\% dos entrevistados a retiram de reservatório, 6\% direta- mente do Rio Miringuava e nenhum deles utilizam poço (FIGURA 2).

FIGURA 3 - Tipo de energia consumida.

Figure 3 - Type of consumed energy.

\section{Tipo de energia consumida}

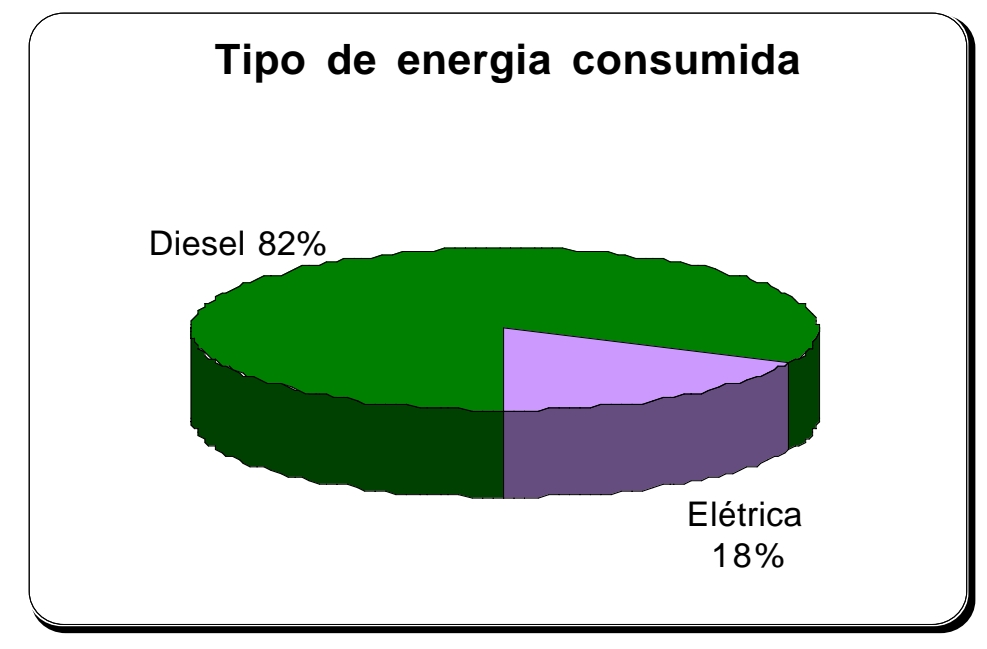


Nesta figura, observa-se que $82 \%$ da energia utilizada para captar água é a diesel, enquanto 18\% usam a energia elétrica.

Na Bacia do Miringuava, grande parte da energia utilizada é a diesel e a maioria dos agricultores não sabe o gasto energético que seus sistemas representam em Reais nem em kw/h, ou seja, não têm informação da potência do motor dos tratores utilizados para captação da água. Caso soubessem, haveria uma maneira de calcular esse gasto energético, onde a potência do motor relacionar- se-ia com a quantidade de diesel em litros/hora e multiplicar-se-ia o valor em reais pago pelo diesel resultando o gasto de energia em reais.

A Figura 4 mostra o grau de conhecimento dos agricultores sobre a Lei de Outorga de Direito de Uso da Água. Dos 33 entrevistados, 88\% disseram ter conhecimento sobre a Lei, e $12 \%$ afirmaram não a conhecer. Vale esclarecer que o significado da palavra conhecer para os que responderam "sim", é simplesmente já terem ouvido, mas nada ou muito pouco sabiam efetivamente.

\section{FIGURA 4 - Conhecimento sobre a Lei de Outorga de Direito de Uso da Água.}

Figure 4 - Knowledge on the Law of Grant of Right of Water Use.



Com o conceito de escassez surge 0 conceito valor econômico da água. Esse valor funciona como um mecanismo de gerenciamento dos recursos hídricos, que tem um viés lógico: tendo que pagar a utilização da água se torna mais racional e cuidadosa. Quanto mais cara ela for, mais racional será seu uso. Desse conceito, surge a Lei da Outorga de Direito de Uso da Água, que é um mecanismo de gerenciamento dos recursos hídricos. Com esta Lei, pretende-se atribuir preços diferenciados conforme o uso da água, entre eles a agricultura irrigada. Para se especificar a quantidade, a destinação - agricultura, abastecimento, geração de energia, etc. - e o preço a ser pago define-se os critérios para a outorga.

Para se evitar o prejuízo a pessoas por essa cobrança de uso por não poderem pagar, a Lei 9.433 traz o conceito de "vazão insignificante", ou seja, a água usada por pequenos usuários, como os agricultores da Bacia do Rio Miringuava, não seriam submetidos à cobrança.

Por um lado isso os favoreceria, pois muitos deles relataram que se houvesse a necessidade de um dia precisarem pagar, seria mais vantajoso pararem suas produções e mudarem de ramo do que passarem a ter mais um gasto em seus orçamentos. Por outro lado, se houvesse a necessidade de pagarem, o uso da água certamente seria mais sustentável pois, pelo menos dessa forma, a água teria um valor para eles.

Na Tabela 3, os dados foram organizados a fim de se saber qual é o método de irrigação utilizado, se os entrevistados possuem algum tipo de assistência técnica e se eles utilizam a quimigação - aplicação de fertilizantes e/ ou pesticidas diluídos na água que será usada para a irrigação. 
TABELA 3 - Assistência técnica, método de irrigação utilizado e utilização de quimigação.

Table 3 - Technical assistanœ, irrigation method and chymigation used.

\begin{tabular}{lr|lr|rr}
\hline Assistência técnica & \multicolumn{2}{|l}{$\begin{array}{l}\text { Método de } \\
\text { irrigação utilizado }\end{array}$} & \multicolumn{2}{l}{$\begin{array}{l}\text { Utilização de } \\
\text { quimigação }\end{array}$} \\
\hline Sim & 22 & Aspersão & 30 & Sim & 3 \\
Emater & 13 & $\begin{array}{l}\text { Gotejamento } \\
\text { Aspersão e }\end{array}$ & 2 & Não & \\
Eng $^{\circ}$ Agrônomo de cooperativas & 3 & Gotejamento & 1 & \\
Eng $^{\circ}$ Agrônomo particular & 3 & & & \\
Emater e Eng ${ }^{\circ}$ Agrônomo & 3 & & & \\
Não & 11 & & & \\
\hline
\end{tabular}

As Figuras 5 e 6 mostram os principais métodos de irrigação utilizados pelos produtores e se esses possuem assistência técnica na referida Bacia.

FIGURA 5 - Método de irrigação.

Figure 5 - Irrigation method.

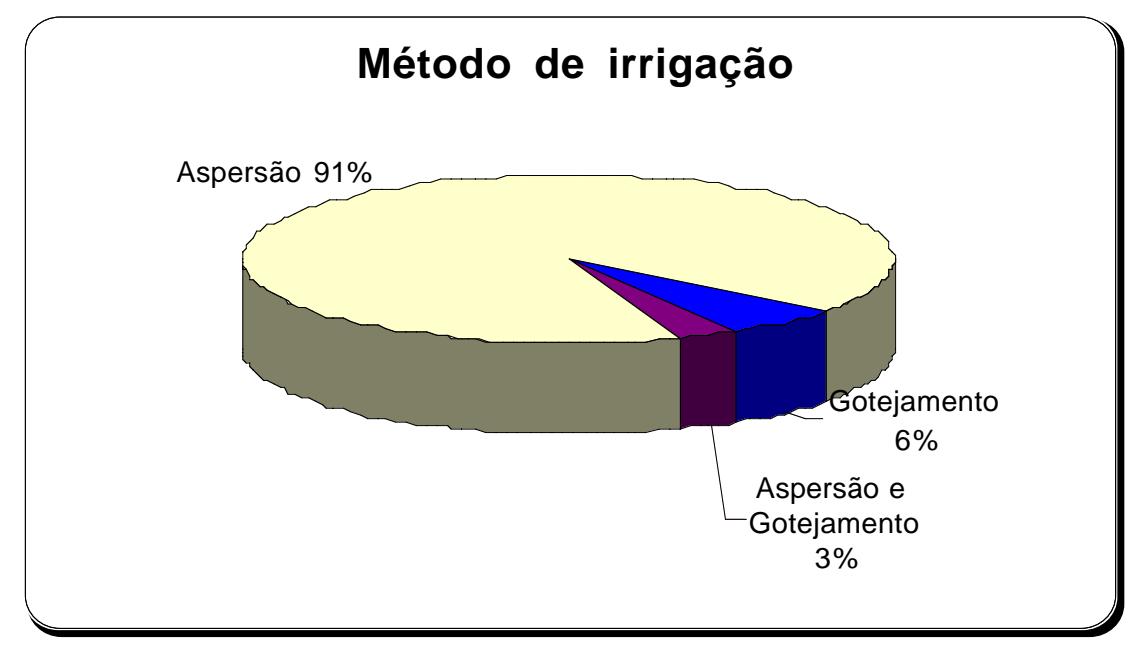

Quanto ao método de irrigação utilizado, ocorre que 91\% são por aspersão, 6\% por gotejamento e $3 \%$ utilizam ambos. 


\section{FIGURA 6 - Assistência Técnica.}

Figure 6 - Technical assistance.

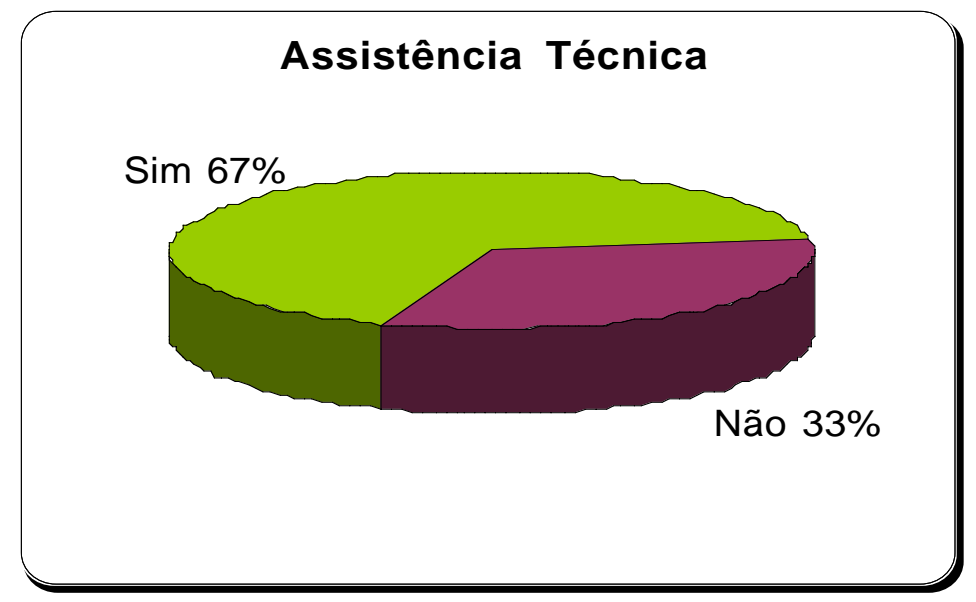

Do total, $67 \%$ dos agricultores possuem assistência técnica e 33\% não. Dos que são atendidos, 13 agricultores contam com os serviços da EMATER, 3 com Engenheiros Agrônomos de cooperativas e lojas de insumos onde efetuam suas compras, 3 com Engenheiros Agrônomos particulares e outros 3 contam com a assistência da EMATER e com Engenheiros de cooperativas.

Para que o manejo racional da água ocorra é fundamental o acompanhamento de profissionais especializados que conduzam os agricultores a uma maior eficiência de produção e, conseqüen- temente, um maior respeito ao ambiente. A frequêencia das visitas geralmente ocorre quando necessário para solucionar um problema no cultivo das hortaliças. Porém, um fator alarmante é o fato que os agricultores informaram que a assistência técnica não os instrui quanto ao manejo da água utilizada. $\mathrm{O}$ atendimento se limita à cultura e acompanhamento da produção, mas quanto à água utilizada, nenhum deles disse receber instruções.

A Figura 7 mostra a porcentagem de agricultores que utilizam a quimigação -aplicação de fertilizantes e/ ou pesticidas diluídos na água que será usada para a irigação - em seus processos produtivos.

\section{FIGURA 7 - Utilização de Quimigação.}

Figure 7 - Chymigation use.

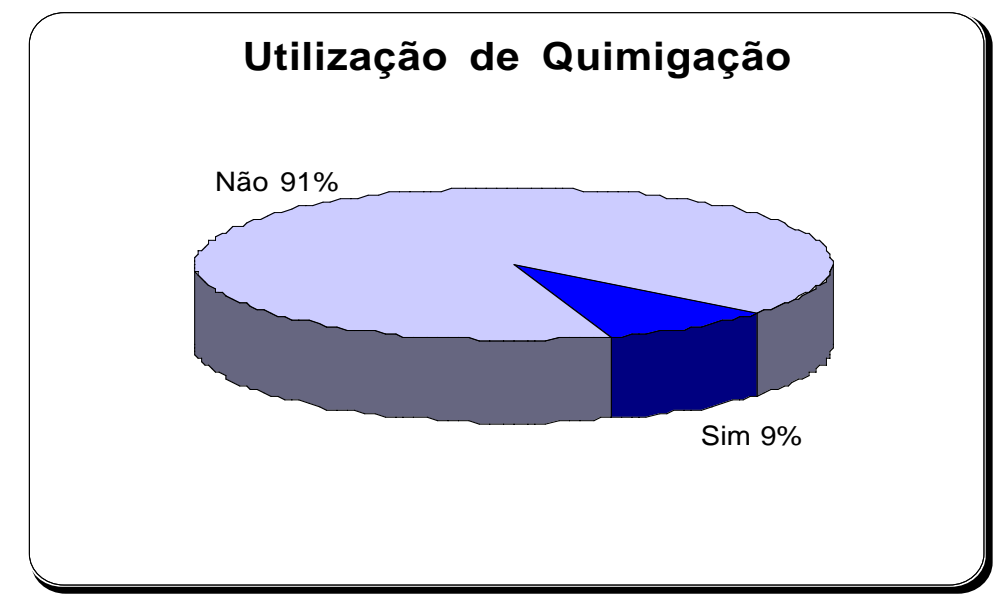

Questionados sobre a utilização de quimigação, 91\% dos agricultores afirmaram não usá-la e 9\% sim. 


\section{Conclusão}

No que se refere especificamente à questão da água, o Brasil, apesar de sua riqueza hídrica, também vem apresentando focos de escassez comparados aos de países desenvolvidos, principalmente nas regiões Sul, Sudeste e Centro-Oeste, onde se concentram os maiores índices nacionais de produção agrícola e, sobretudo, de demanda de água. Aliado a esses fatores encontra-se um problema maior de consciência alojado no modelo que rege a sociedade moderna, que alia um consumismo desenfreado da água à cultura do desperdício.

O consumo de água na área de estudo se apresentou relativamente alto. Apesar de não ter sido programada a medição de água no momento em que o sistema começa a funcionar, constatouse por meio da entrevista que a água é utilizada sem nenhum critério. A irrigação é feita por suposições de quantidades satisfatórias de água sem haver preocupação de excesso de utilização e retirada de água.

Foram constatados dois métodos de irrigação na Bacia do Miringuava, a aspersão e o gotejamento. Dos 33 agricultores entrevistados, 30 utilizam o método por aspersão, 2 por gotejamento e 1 agricultor utiliza os dois métodos.

Com esses dados, concluiu-se que o uso da água na agricultura irrigada na região não é eficiente, em função das condições de manutenção verificadas, que apresentavam vazamentos e entupimentos nos canos de distribuição da água e, também, pelo descuido dos agricultores com esses sistemas e pelas condições observadas nos estudos de campo.
Não foi possível estimar, neste estudo, o consumo de água utilizada pelos sistemas de irrigação, pois $94 \%$ dos agricultores não souberam informar a sua vazão. Assim, foi impossível estimar o tempo diário de aplicação de água e a real quantidade necessária ao consumo das plantas. Seria necessário dispor de um tempo maior para medir a vazão a partir do momento em que o sistema de irrigação começasse a funcionar.

\section{Referências}

KARAM, K. F. Agricultura orgânica: estratégia para uma nova ruralidade. 2001. 232 f. Tese (Doutorado em Meio Ambiente e Desenvolvimento), UFPR- Universidade Federal do Paraná, Curitiba, 2001.

LUNARDON, M. Irrigação na madrugada. [Mensagem pessoal]. Mensagem recebida por <lunardon@pr.gov.br>em 6 de novembro de 2003.

MOURA, E. N. Avaliação do desempenho de sistemas de irrigação pressurizados em fruticultura. 1999. 59 f. Dissertação (Mestrado) UNESP, Botucatu, 1999.

TELLES, D. Água na agricultura e pecuária. In: REBOUÇAS, Aldo da Cunha; BRAGA, B.; TUNDISI, J. G. Águas doces no Brasil: capital ecológico, uso e conservação. São Paulo, SP: Escrituras, 1999. p. 305-337.

TUNDISI, J. G. Água no século XXI: Enfrentando a escassez. São Carlos: RiMa, IEE, 2003.

Recebido: 24/02/2005

Aprovado: 30/06/2005 